\title{
Endoscopic submucosal dissection for gastric duplication cyst with heterotopic
} pancreas

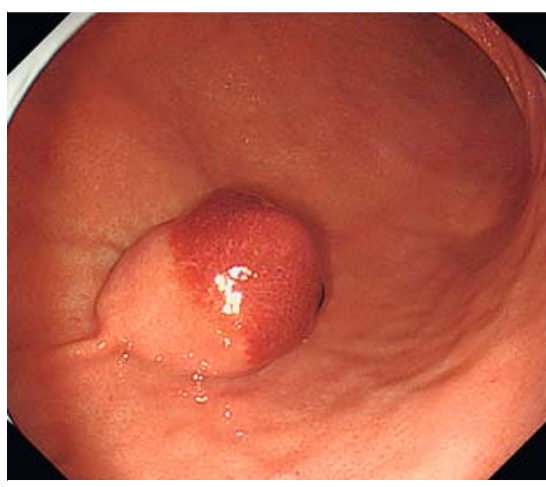

- Fig. 1 A subepithelial tumor with severe erythema and hemorrhagic spots was seen in the gastric lower body.

A 63-year-old man presented with a gastric subepithelial tumor, incidentally detected on screening endoscopy. A subepithelial tumor, approximately $30 \mathrm{~mm}$ in size and with a positive cushion sign, was observed on the greater curvature of the gastric lower body (> Fig. 1). Severe erythema and hemorrhagic spots were seen on its surface. On endoscopic ultrasonography, the lesion was anechoic, mainly confined to the submucosal layer, and had a small branch-shaped hypoechoic portion in the cystic wall (-Fig.2). Endoscopic submucosal dissection (ESD) was suggested in order to prevent bleeding ( $\triangleright$ Video $\mathbf{1}$ ).

After marking the tumor borders, a $0.9 \%$ saline solution with epinephrine and indigo carmine was injected into the submucosal layer. Subsequently, a circumferential mucosal incision was made with a dual knife and submucosal dissection was performed with an insulated-tipped knife. During dissection, the tumor was tightly attached to the proper muscle layer; therefore, a clip attached with dental floss was deployed to secure the dissection plane between the tumor and muscle layer ( $\triangleright$ Fig. 3 ). The tumor was safely and completely resected ( $\mathbf{F i g . 4}$ ). Histopa-

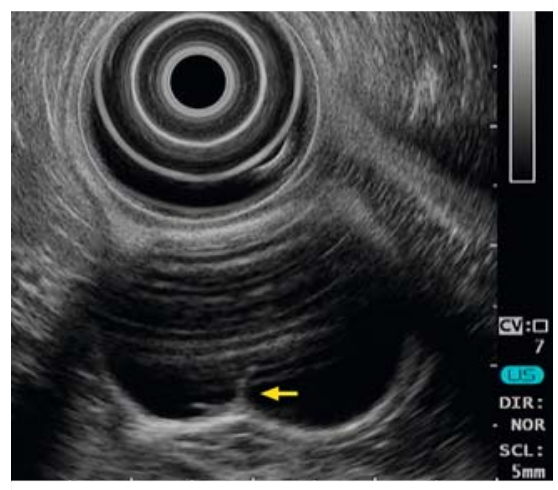

- Fig. 2 On endoscopic ultrasonography, the lesion was anechoic, mainly confined to the submucosal layer, and a small branch-shaped hypoechoic portion was identified in the cystic wall (arrow).

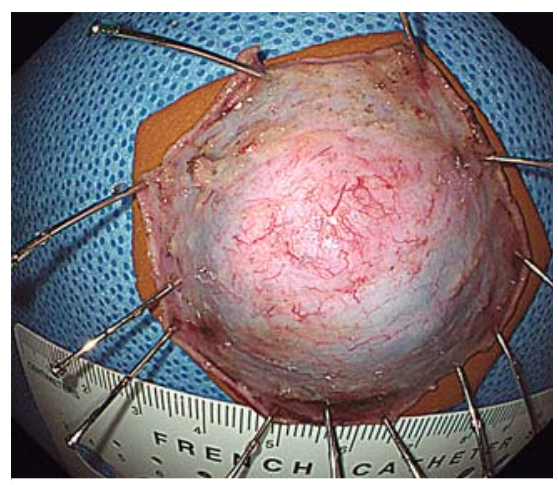

Fig. 4 The inner surface of the resected specimen.

thologically, the cystic lesion was lined with columnar epithelial mucosa and had its own muscle layer, and ectopic pancreatic tissue of acinar structure was present in the cystic wall ( $\mathbf{F i g . 5}$ ). The patient did not develop any adverse events and was discharged after 2 days.

Gastric duplication cysts comprise about $2 \%-9 \%$ of gastrointestinal duplication cysts [1]. Most are cystic, occurring along the greater curvature of the stomach without communicating with it [2]. Ectopic pancreatic tissue is found in the

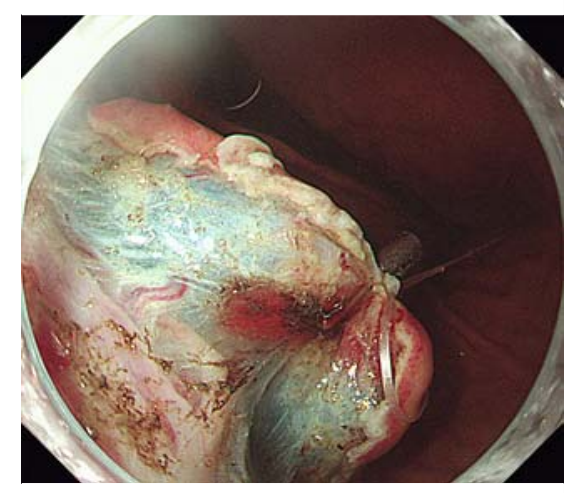

- Fig. 3 A clip attached with dental floss was deployed to secure the dissection plane between the tumor and the muscle layer.

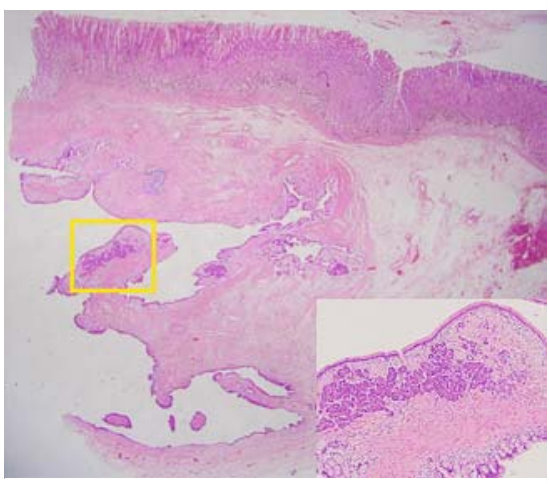

- Fig. 5 Histopathologically, the cystic lesion was lined with columnar epithelial mucosa and had its own muscle layer (hematoxylin and eosin [H\&E] stain, $\times 12.5$ ). Ectopic pancreatic tissue of acinar structure was also present in the cystic wall (boxed area, H\&E stain, $\times 100$ ).

wall in up to $37 \%$ [3]. The conventional treatment for removal is surgical resection; ESD is an alternative modality. Due to the tight attachment of the cyst to the muscle layer, dental floss and clip traction is an efficient and safe method for en bloc resection.

Endoscopy_UCTN_Code_CCL_1AB_2AD_3AF 


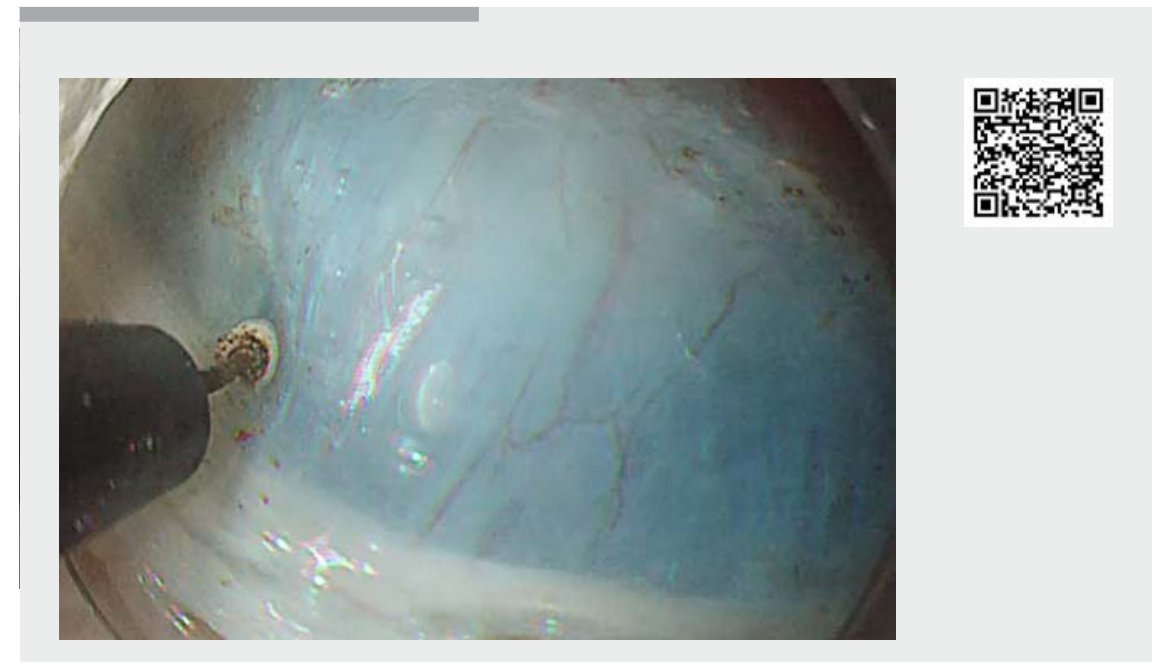

Video 1 Endoscopic submucosal dissection of a gastric duplication cyst.

\section{ENDOSCOPY E-VIDEOS}

https://eref.thieme.de/e-videos

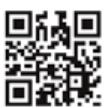

Endoscopy E-Videos is a free access online section, reporting on interesting cases and new

techniques in gastroenterological endoscopy. All papers include a high quality video and all contributions are freely accessible online.

This section has its own submission website at https://mc.manuscriptcentral.com/e-videos

\section{Competing interests}

The authors declare that they have no conflict of interest.

The authors

\section{Gwang Ha Kim¹, Moon Won Lee', Bong Eun} Lee $^{1}$, Do Youn Park ${ }^{2}$

1 Department of Internal Medicine, Pusan National University School of Medicine and Biomedical Research Institute, Pusan National University Hospital, Busan, Korea

2 St. Mary Pathology Laboratory, Busan, Korea

Corresponding author

\section{Gwang Ha Kim, MD, PhD}

Department of Internal Medicine, Pusan National University School of Medicine and Biomedical Research Institute, Pusan National University Hospital, 179 Gudeok-ro, Seo-Gu, Busan 49241, Korea

Fax: +82-51-2448180

doc0224@pusan.ac.kr

\section{References}

[1] Kim DH, Kim JS, Nam ES et al. Foregut duplication cyst of the stomach. Pathol Int 2000; 50: $142-145$

[2] Eom JS, Kim GH, Song GA et al. Gastric duplication cyst removed by endoscopic submucosal dissection. Korean J Gastroenterol 2011; 58: 346-349

[3] Macpherson RI. Gastrointestinal tract duplications: clinical, pathologic, etiologic, and radiologic considerations. Radiographics 1993; 13: 1063-1080

\section{Bibliography}

Endoscopy 2021; 53: E19-E20

DOI $10.1055 / \mathrm{a}-1173-7326$

ISSN $0013-726 \mathrm{X}$

published online 29.5.2020

(c) 2020. Thieme. All rights reserved.

Georg Thieme Verlag KG, Rüdigerstraße 14,

70469 Stuttgart, Germany 